\title{
ER stress does not cause upregulation and activation of caspase-2 to initiate apoptosis
}

\author{
JJ Sandow ${ }^{1,2}$, L Dorstyn $^{3,4,5}$, LA O’Reilly ${ }^{1,2}$, M Tailler ${ }^{1,2}$, S Kumar ${ }^{\star, 3,4,5}$, A Strasser ${ }^{\star, 1,2}$ and PG Ekert ${ }^{\star, 1,2}$
}

A recent report claimed that endoplasmic reticulum (ER) stress activates the ER trans-membrane receptor IRE1 $\alpha$, leading to increased caspase-2 levels via degradation of microRNAs, and consequently induction of apoptosis. This observation casts caspase-2 into a central role in the apoptosis triggered by ER stress. We have used multiple cell types from caspase-2-deficient mice to test this hypothesis but failed to find significant impact of loss of caspase-2 on ER-stress-induced apoptosis. Moreover, we did not observe increased expression of caspase-2 protein in response to ER stress. Our data strongly argue against a critical role for caspase-2 in ER-stress-induced apoptosis.

Cell Death and Differentiation (2014) 21, 475-480; doi:10.1038/cdd.2013.168; published online 29 November 2013

Secreted and trans-membrane proteins are shuttled into the secretory pathway by translocation to the endoplasmic reticulum (ER). Proteins must be correctly folded before being transported to their target compartment, with incorrectly folded protein being targeted for degradation. ${ }^{1}$ The accumulation of mis-folded protein in the ER can be caused by multiple physiological and pathological conditions and results in ER stress. Cellular responses to ER stress are regulated by ER localized stress receptors, but the mechanisms by which this cytotoxic insult triggers apoptosis are not fully resolved although the $\mathrm{BH}$-only proteins $\mathrm{Bim}^{2}$ and $\mathrm{Puma}^{3,4}$ have both been demonstrated to contribute to this process.

Recently, Upton et al..$^{5}$ reported a novel mechanism whereby the ER trans-membrane receptor IRE $1 \alpha$ cleaved several microRNAs, which in turn promoted the de-repression of caspase-2 translation, leading to activation of this caspase and consequent cell death. Thus, when ER stress was induced in mouse embryonic fibroblasts (MEFs) by treatment with Brefeldin A (BFA), caspase-2 protein levels increased dramatically, followed by proteolytic activation of this caspase and induction of apoptosis.

These results imply that caspase- 2 is required for apoptosis triggered by ER stressors. This is an important observation as, to date, the physiological role of caspase-2 has remained obscure. Previous analysis of caspase-2-deficient mice did not identify any developmental abnormalities that might be expected from a defect in ER-stress-induced apoptosis, ${ }^{6}$ although evidence does indicate that caspase-2 has a tumorsuppressive role in certain transgenic mouse cancer models ${ }^{7-9}$ and an anti-ageing role. ${ }^{10}$ In this study, we have sought to clarify the role of caspase- 2 in the cellular response to ER stress. In contrast to the published report, ${ }^{5}$ we found that caspase-2 levels were not upregulated by drugs that induce ER stress nor was there any significant impact of loss of caspase-2 on the extent of cell death elicited by ER stress. Our data demonstrate that caspase-2 levels are not modulated by ER stress and that caspase- 2 is not required for the induction of apoptosis following ER stress. This work emphasizes the importance of independent repetition of results and the use of independent cell preparations in order to establish the veracity of new physiological roles for proteins, such as caspase-2.

\section{Results}

To evaluate the requirement for caspase-2 in apoptosis induced by ER stress, we exposed a range of primary and immortalized cell types from wild-type (WT) and caspase-2deficient mice to the same ER-stress-inducing compounds employed in the study by Upton et al. ${ }^{5}$ We treated primary and immortalized MEFs from WT and Caspase $-2^{-/-}$mice with the ER-stress-inducing drugs BFA, Thapsigargin (TG) or Tunicamycin (TM). In both primary and immortalized MEFs, we observed an equivalent amount of cell death between WT and Caspase- $2^{-1-}$ cells across a broad range of drug concentrations and over an extended time course (Figures $1 \mathrm{a}$ and $\mathrm{b}$ ). Any small differences that were observed between WT and Caspase- $2^{-/-}$cells were not consistent between the primary and immortalized MEFs. As a control, we used MEFs derived from $\mathrm{Bax}^{-1-} ; \mathrm{Bak}^{-1-}$ mice. ${ }^{11,12}$ As expected given the essential overlapping roles of Bax and Bak in the intrinsic (also called Bcl-2-regulated, mitochondrial or stress-induced)

\footnotetext{
${ }^{1}$ The Walter and Eliza Hall Institute of Medical Research, Parkville, VIC 3052, Australia; ${ }^{2}$ Department of Medical Biology, The University of Melbourne, Parkville, VIC 3052, Australia; ${ }^{3}$ The Centre for Cancer Biology, SA Pathology, Adelaide, SA 5000, Australia; ${ }^{4}$ Department of Medicine, University of Adelaide, Adelaide, SA 5005, Australia and ${ }^{5}$ Division of Health Sciences, University of South Australia, Adelaide, SA 5001, Australia

*Corresponding authors: S Kumar, The Centre for Cancer Biology, SA Pathology, Adelaide, SA 5000, Australia. Tel: +6188222 3738 ; Fax: +61 882223162 ; E-mail: Sharad.Kumar@health.sa.gov.au

or A Strasser or PG Ekert, The Walter and Eliza Hall Institute of Medical Research, Parkville, VIC 3052, Australia. Tel: +61 393452624 ; Fax: +61 393450852 (AS) or Tel: + 6139345 2970; Fax: +51 393450852 (PGE); E-mail: strasser@wehi.edu.au or ekert@ wehi.edu.au Keywords: caspase-2; ER stress; apoptosis

Abbreviations: ER, endoplasmic reticulum; MEF, mouse embryonic fibroblast; FDM, factor-dependent myeloid; BFA, Brefeldin A; TG, Thapsigargin; TM, Tunicamycin Received 11.9.13; revised 13.10.13; accepted 29.10.13; Edited by G Melino; published online 29.11.13
} 
a

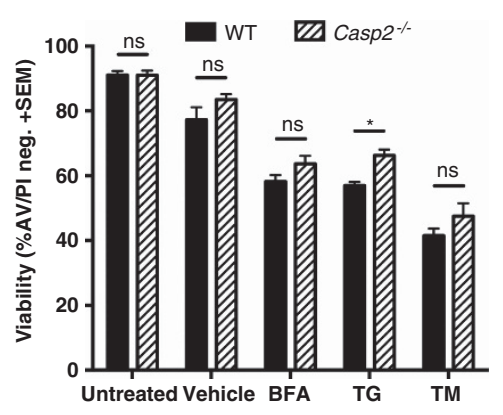

b

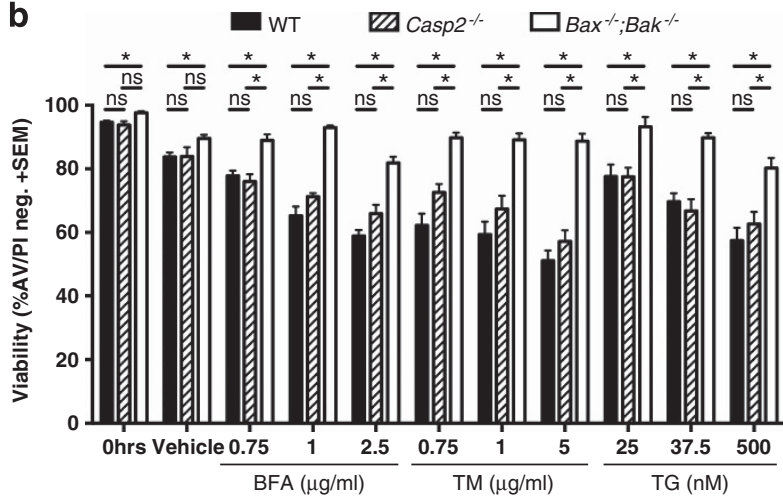

C

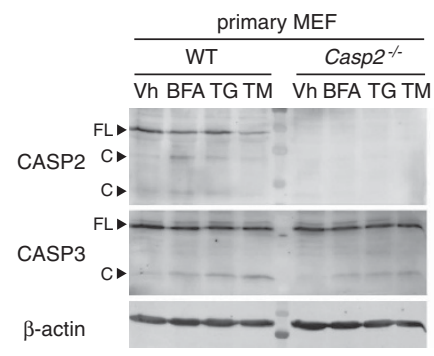

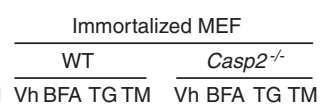

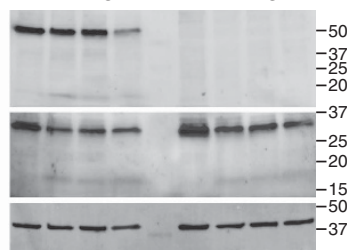

d

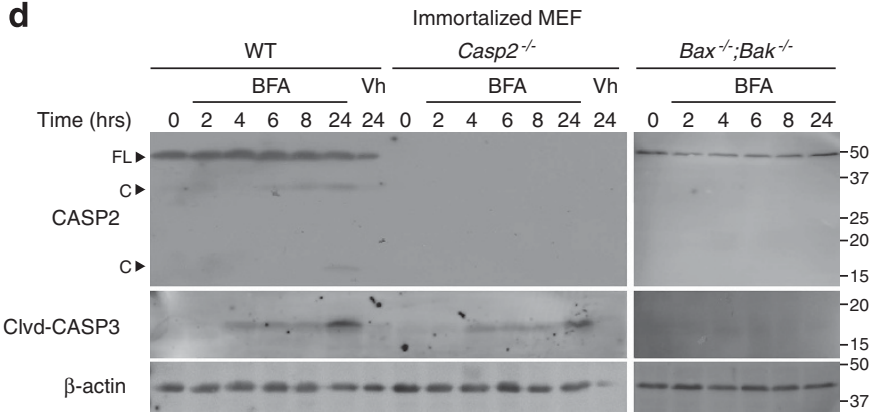

Figure 1 Caspase-2 is dispensable for ER-stress-induced killing of MEFs. (a) WT and caspase-2 ${ }^{-1-}$ primary MEFs (WT $n=5$, caspase-2 $2^{-1-} n=4$ ) were treated with BFA $(2.5 \mu \mathrm{g} / \mathrm{ml})$, TG $(1 \mu \mathrm{M}), \mathrm{TM}(5 \mu \mathrm{g} / \mathrm{ml})$ or vehicle for $24 \mathrm{~h}$ and Annexin $\mathrm{V}$ negative/PI negative (i.e. surviving) cells were quantified by flow cytometry. (b) Spontaneously immortalized MEFs (WT $n=4-8$, caspase-2 ${ }^{-/} n=5-9, \mathrm{Bax}^{-/-}$;Bak ${ }^{-/}-n=4-5$ ) were treated with BFA, TG, TM (at the doses indicated) or vehicle for $24 \mathrm{~h}$ and Annexin $\mathrm{V}$ negative/PI negative (i.e. surviving) cells were quantified by flow cytometry. (c) Primary MEFs and spontaneously immortalized MEFs were treated with ER-stress-inducing drugs for $24 \mathrm{~h}$ as described in a. Cell lysates were analyzed by immunoblotting using antibodies against caspase-2 (clone 11B4), caspase-3 and $\beta$-actin (loading control). (d) WT, Caspase-2 $2^{-1-}$ and $\mathrm{Bax}^{-1-} ; \mathrm{Bak}^{-1-}$ spontaneously immortalized MEFs were treated with BFA $(2.5 \mu \mathrm{g} / \mathrm{ml})$ over the indicated time course. Cell lysates were analyzed by immunoblotting using antibodies against caspase-2 (clone 11B4), cleaved (i.e. activated) caspase-3 and $\beta$-actin (loading control). Full-length proteins are designated (FL) with cleavage products following ER stress indicated as (C). $P$-values were calculated using unpaired $t$-test, (ns) signifies $P>0.05,\left({ }^{*}\right)$ signifies $P<0.05$

apoptosis pathway, ${ }^{11,13}$ the Bax/Bak double-deficient cells were largely resistant to apoptosis induced by these drugs (Figure 1b). Moreover, in contrast to the previous publication, ${ }^{5}$ we did not observe any increase in caspase-2 protein expression at any time point following induction of ER stress in WT or $\mathrm{Bax}^{-1-} ; \mathrm{Bak}^{-1-}$ MEFs (Figures 1c and d). This indicates that caspase-2 is not required for apoptosis induced by BFA, TG or TM in MEFs and that caspase-2 expression was not increased in response to ER stress.

To further investigate the involvement of caspase-2 in the response to ER-stress-induced apoptosis, we exposed primary mouse thymocytes, mature $\mathrm{T}$ lymphocytes and Hoxb8-transformed IL-3-dependent myeloid progenitors (factor-dependent myeloid (FDM)) from WT and Caspase-2 ${ }^{-/-}$ mice to BFA and TG. As a control to reveal the impact of a substantial block in the intrinsic apoptotic pathway, we used primary mouse thymocytes and FDM cells from $\mathrm{Bax}^{-1-}$; $\mathrm{Bak}^{-1-}$ mice. The WT and Caspase- $2^{-/-}$thymocytes, T lymphocytes and FDM cells were either equally susceptible to ER stress induced across a broad range of drug concentrations and over an extended time course of analysis or in the case of caspase-2 $2^{-/-}$FDM cells appeared slightly more susceptible to BFA and low doses of TG at early time points than WT cells (Figures 2a, c and e; Supplementary Figure 1). This shows that caspase-2 is not required for apoptosis induced by BFA or
TG in these cell types. In contrast, the $\mathrm{Bax}^{-1-} ; \mathrm{Bak}^{-1-}$ cells were profoundly resistant to BFA. Although a substantial fraction of $\mathrm{Bax}^{-1-} ; \mathrm{Bak}^{-1-}$ FDMs and thymocytes died after exposure to TG, the numbers of viable cells were still far greater than those observed with WT or Caspase- $2^{-/-}$cells. In contrast to Upton et al., ${ }^{5}$ we did not observe in any of the WT or $\mathrm{Bax}^{-1-} ; \mathrm{Bak}^{-1-}$ cell types examined, an increase in full-length caspase-2 protein levels following ER stress (Figures 2b, d and f; Supplementary Figure 2).

Furthermore, in response to ER stress, caspase-3 was cleaved (and hence activated) over time in both WT and caspase-2-deficient cells, but not in $\mathrm{Bax}^{-1-} ; \mathrm{Bak}^{-/-}$cells. These data demonstrate first, that caspase- 2 was not required for processing and activation of caspase-3, and second that the loss of viability observed in $\mathrm{Bax}^{-1-} ; \mathrm{Bak}^{-1-}$ cells was independent of caspase- 3 activation. It is therefore possible that this death of $\mathrm{Bax}^{-/-} ; \mathrm{Bak}^{-/-}$cells is mediated (at least in part) through a non-apoptotic process. In addition, ER stress resulted in cleavage of caspase-2 only in WT but not in $\mathrm{Bax}^{-1-} ; \mathrm{Bak}^{-1-}$ cells. This is consistent with previous studies using other apoptotic stimuli (e.g. $\gamma$-irradiation ${ }^{6}$ ), and demonstrates that caspase-2 cleavage (as opposed to activation, which does not necessarily require processing ${ }^{14}$ ) constitutes an event that occurs downstream of Bax/Bak activation and the formation of the apoptosome. ${ }^{6}$ 
a

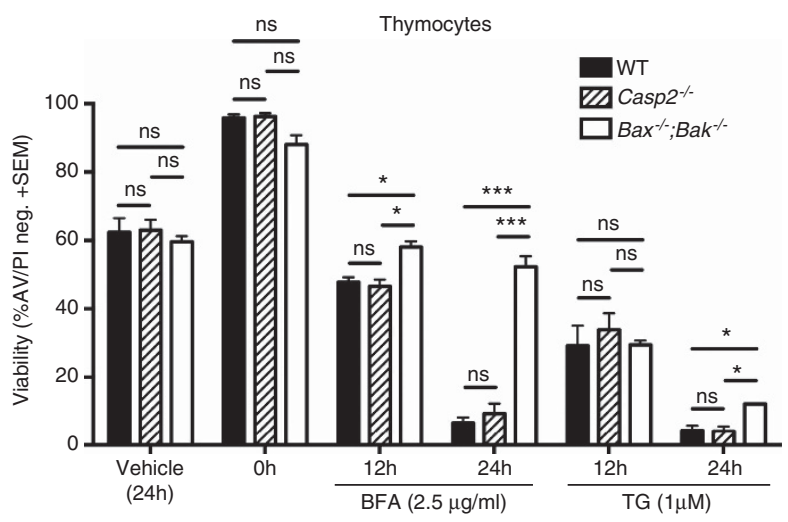

b

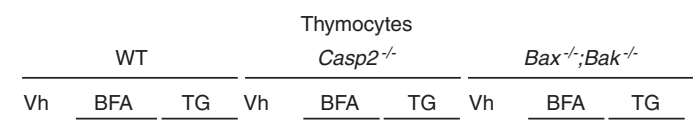

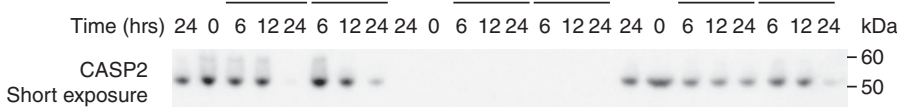
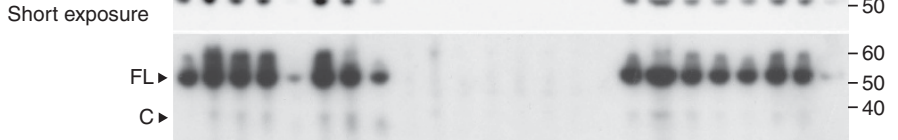

CASP2

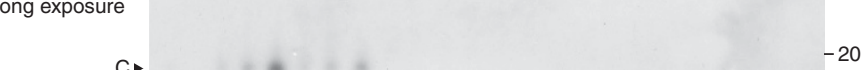

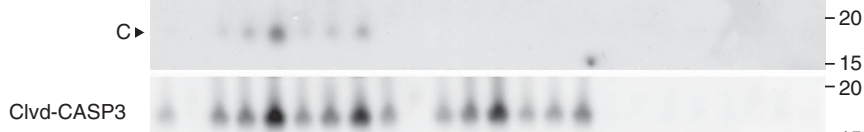

$\beta$-actin

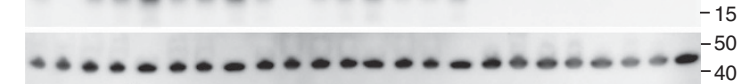

c

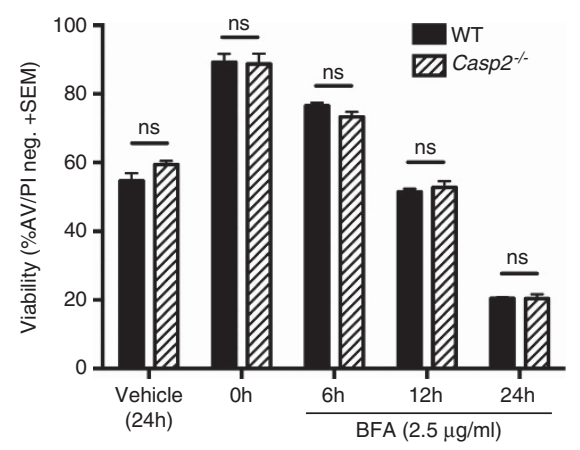

d

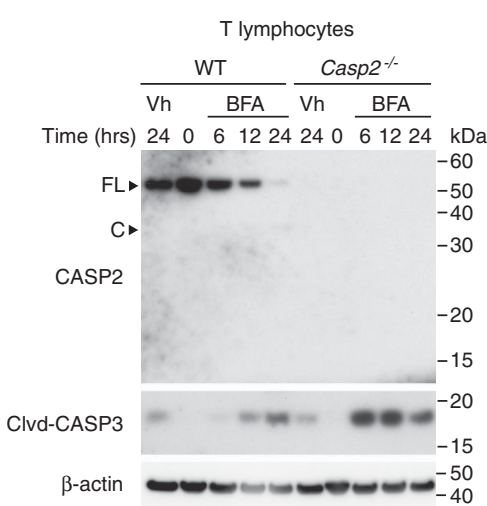

$k \mathrm{ka}$
60
50
40
-30
-20
-15
-20
-15
-50
40

e

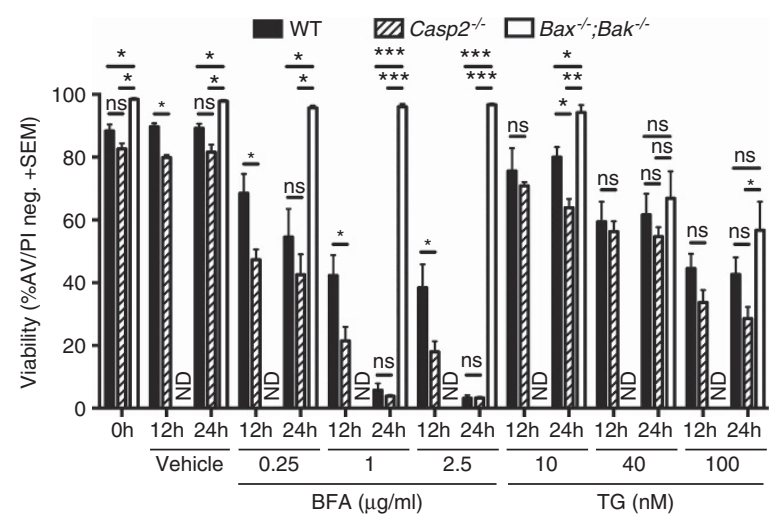

f 
To extend our observations, we used NALM-6, RAJI, MV4-11 and U-937 cells, which are all human leukemia- or lymphoma-derived cell lines. These cells were treated with TM, TG or BFA and examined over a time course for changes in the expression levels of caspase-2 protein (Figure 3; Supplementary Figure 3). Again, there was no significant increase in caspase-2 expression following the induction of
ER stress. Collectively, these results demonstrate that caspase-2 protein expression is not induced in response to ER stress and does not contribute to cell death resulting from ER stress.

We observed abundant full-length caspase-2 in all cell types in the absence of ER stress or any other cytotoxic insult. Perplexingly, over two different studies Upton et al.,

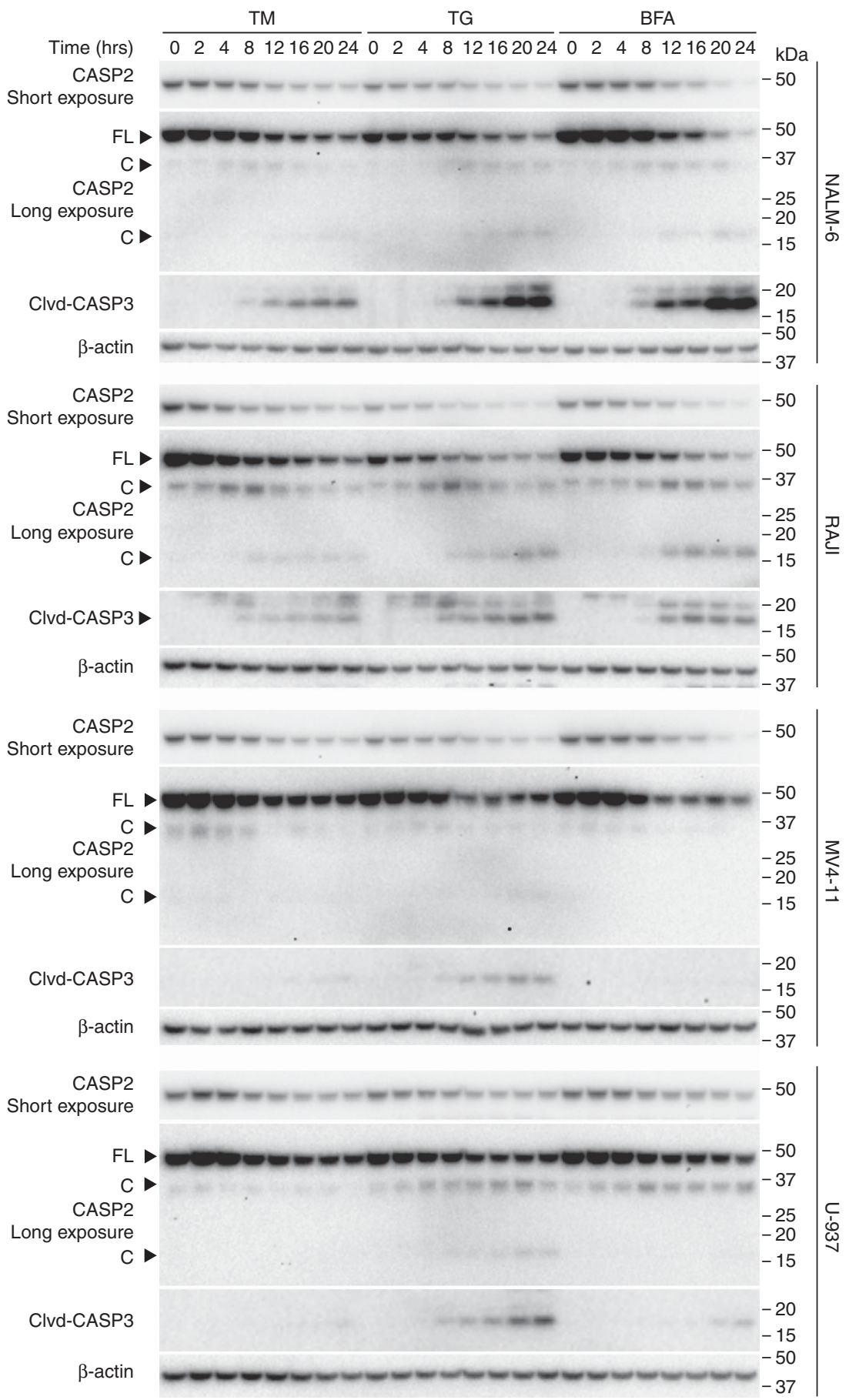

Figure 3 Caspase-2 protein levels are not upregulated following ER stress in several human leukemia- and lymphoma-derived cell lines. NALM-6, RAJl, MV4-11 and U-937 cells were treated with TM $(2.5 \mu \mathrm{g} / \mathrm{ml})$, TG $(2 \mu \mathrm{M})$ or BFA $(2.5 \mu \mathrm{g} / \mathrm{ml})$ over the indicated time course. Cell lysates were analyzed by immunoblotting using antibodies against caspase-2 (clone 10C6), cleaved (i.e. activated) caspase-3 and $\beta$-actin (loading control). Full-length proteins are designated (FL) with cleavage products following ER stress indicated as (C) 
reported strikingly diametrically opposed results on the levels of caspase-2 expression, even in the same cells. These discrepancies could be explained, in part, by differences in the specificity and quality of the various caspase- 2 antibodies used in these two studies. To interrogate this possibility, we compared the antibodies employed by these authors using the same lysates derived from WT and caspase-2 ${ }^{-/-}$ (negative control) thymocytes that had been treated with BFA or vehicle (Figure 4). A monoclonal antibody that we have previously generated (mAb $106^{6}$ ) showed exquisite specificity for caspase-2, whereas the two antibodies used by Upton et al. ${ }^{5}$ in their recent study seem to detect abundant non-specific bands, mostly showing no difference between lysates from thymocytes of WT versus caspase $-2^{-/-}$mice. The caspase-2 antibody from Novus does appear to detect full-length caspase-2 (among many non-specific bands); however, the appearance of any cleavage products is masked by the presence of non-specific bands.

\section{Discussion}

Caspase-2 remains an enigmatic protein with recently established functions in tumor suppression, genomic stability and ageing. $9,10,16,17$ This caspase is evolutionarily highly conserved, yet surprisingly loss of caspase-2 has no significant impact on the development of mice. Caspase-2 ${ }^{-/-}$ mice show mild pre-mature ageing phenotypes but no overt morphological abnormalities; they breed normally and have no clearly recognizable defects in apoptosis across a broad range of cell types. ${ }^{6,18,19}$ Using a large array of primary as well as immortalized mouse and human cell types, our data demonstrate that caspase-2 levels do not increase in response to ER stress and that caspase-2 is not required for ER-stress-induced apoptosis.

The observation that caspase-2 may be involved in the apoptotic response to ER stress ${ }^{5}$ was surprising given the lack of easily recognizable phenotypic abnormalities in caspase-2deficient mice, but important nonetheless because this was a clear indication of a hitherto unrecognized function of this caspase. The model published by Upton et al. proposed that in response to ER stress caspase-2 protein levels were upregulated due to IRE $1 \alpha$-mediated cleavage of microRNAs that otherwise repressed caspase- 2 translation. Regardless of any regulation by microRNAs, this model casts caspase-2 in a central role in the apoptosis that occurs in response to ER stress. In contrast to these published data, ${ }^{5}$ we did not observe any increase in caspase-2 protein expression at various time points or doses following ER-stress-inducing drugs, nor any significant difference in viability between WT versus caspase-2-deficient cells following treatment with different ER-stress-inducing drugs. It is unclear why our results differ from Upton et al. as we used the same cell lines (and additional primary and immortalized cell lines) with the same drugs, doses and treatment time points. One potential reason for the discrepancies in our observations is the different antibodies used to detect caspase-2 protein. We found the antibodies used by Upton et al. were unreliable and largely non-specific (Figure 4).

Our findings are supported by previous studies, which treated a variety of caspase $-2^{-/-}$cells with drugs to induce ER stress, also finding no difference in cell viability when compared with WT cells. ${ }^{20}$ Moreover, our data demonstrate that although IRE $1 \alpha$ may regulate the abundance of specific microRNAs in response to ER stress as reported in the original study, caspase-2 protein expression is not regulated by any such changes. We did not analyze changes to caspase-2 mRNA expression in response to ER stress as regulation of gene expression by microRNAs can occur by blocking translation of mRNA in addition to degradation of mRNA transcripts; therefore, this approach is likely to be uninformative. Regardless, our protein expression and cell survival analyses demonstrate clearly that caspase-2 expression is not regulated in response to ER stress and, even more importantly, that caspase-2 is not required for ER stressinduced cell death.

\section{Materials and Methods}

Mice. All experiments with mice were approved by The Walter and Eliza Hall Institute Animal Ethics committee and SA Pathology Animal Ethics Committee. The caspase-2 $2^{-1-6}$ and $\mathrm{Bax}^{-/-} ; \mathrm{Bak}^{-/-}$mice ${ }^{11,21}$ have been previously described. The caspase- $2^{-1-}, B a x^{-/-}$and $B a k^{-/-}$mice (the latter two used

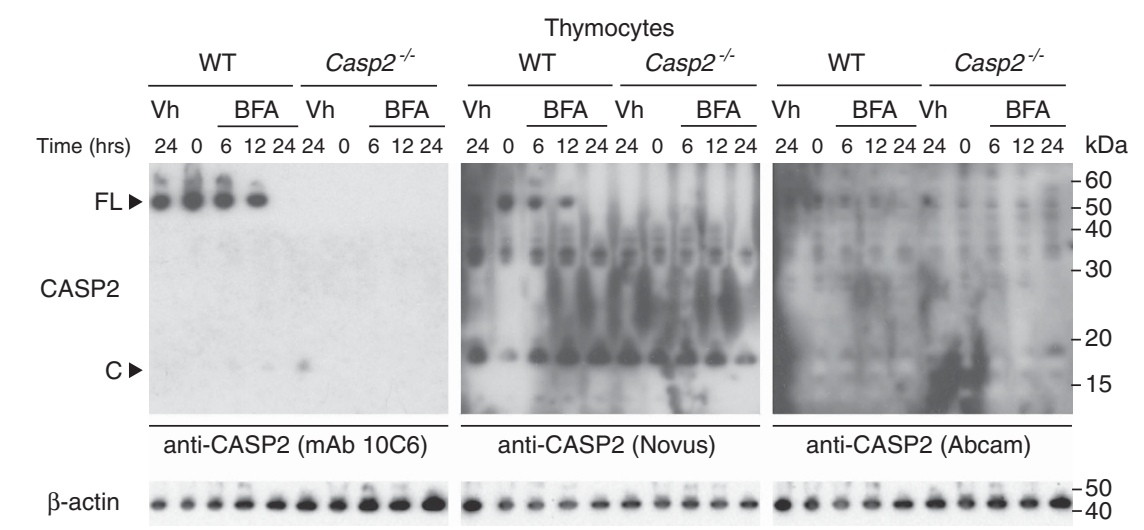

Figure 4 Comparison of the specificities of different caspase-2 antibodies. Primary thymocytes from WT and caspase- $2^{-1-}$ mice were treated with BFA (2.5 $\left.\mu \mathrm{g} / \mathrm{ml}\right)$ or vehicle over the indicated time course. Cell lysates were analyzed by immunoblotting using the following antibodies against caspase-2: clone $10 \mathrm{C} 6$ (Enzo ${ }^{6}$ ), Novus Y61 \#NB$110-55655$ or Abcam \#ab18737 or were probed, as a loading control, with an antibody to $\beta$-actin. All images from blots produced by probing with the various antibodies to caspase-2 were exposed for an equal period of time. Full-length proteins are designated (FL) with cleavage products following ER stress indicated as (C) 
to generate the $\mathrm{Bax}^{-/-} ; \mathrm{Bak}^{-/-}$mice) were all originally generated on a mixed C57BL/ $6 \times 129$ SV genetic background using 129SV-derived ES cells but were subsequently backcrossed onto a C57BL/6 background for 10 to $>20$ generations.

Survival assays with primary cells and cell lines. Primary MEFs were isolated and cultured as described previously. ${ }^{17,22}$ Spontaneously immortalized MEFs were generated by serial passaging of MEFs in culture, using the $3 T 3$ subculture method. ${ }^{16}$ Primary mouse thymocytes were isolated and cultured as described previously. ${ }^{6}$ WT, Caspase- $-2^{-/-}$and $\mathrm{Bax}^{-/-} ; \mathrm{Bak}^{-1-}$ FDM cells were generated as described previously. ${ }^{23}$ WT mice were reconstituted with $\mathrm{Bax}^{-/-} ; \mathrm{Bak}^{-/-}$hematopoietic stem cells (using fetal liver cells from E14.5 embryos) as described previously and were a kind gift from Francine Ke. ${ }^{21}$ T lymphocytes were purified from spleens and lymph nodes of WT and caspase-2 ${ }^{-1-}$ mice as described previously. ${ }^{24}$ BFA, TG and TM (Sigma, St. Louis, MO, USA) were dissolved in dimethylsulphoxide (experiments with MEFs) or ethanol (experiments with FDMs, thymocytes and T lymphocytes). For human leukemia- or lymphoma-derived cell lines, BFA was dissolved in DMEM (Gibco, Mulgrave, VIC, Australia), TM was dissolved in ethanol and TG was dissolved in dimethylsulphoxide. Cell viability was determined by staining cells with fluoroscein isothiocyanate-coupled Annexin V (Invitrogen, Mulgrave, VIC, Australia) in balanced salt solution including $5 \mathrm{mM} \mathrm{CaCl}$ and propidium iodide (PI $5 \mu \mathrm{g} / \mathrm{ml}$, Sigma) followed by flow cytometric analysis in a LSRIl flow cytometer (Becton Dickinson, Franklin Lakes, NJ, USA) or a FC500 flow cytometer (Beckman Coulter, Lane Cove, NSW, Australia).

Western blot analysis. Total cell lysates were prepared by lysing cells either directly into SDS (sodiumdodecylsulphate) containing gel loading buffer (250 $\mathrm{mM}$ Tris- $\mathrm{HCl}, 4 \%$ glycerol, $5 \%$ SDS, $0.25 \%$ bromophenol blue, 5\% 2-mercaptoethanol; for experiments with thymocytes, T lymphocytes and FDM

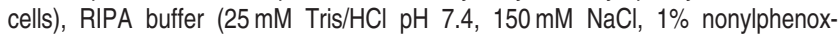
ylpolyethoxylethanol (NP-40), $1 \%$ sodium deoxycholate, $0.1 \%$ SDS in the presence of protease/phosphatase inhibitor cocktail (Thermo Scientific, Waltham, MA, USA); for experiments with MEFs) and lysed by freeze/thaw cycles in liquid $\mathrm{N}_{2}$ and ice cold water or in ONYX lysis buffer $(20 \mathrm{mM}$ Tris-HCl pH 7.4, $135 \mathrm{mM}$ $\mathrm{NaCl}, 1.5 \mathrm{mM} \mathrm{MgCl}_{2}, 1 \mathrm{mM} \mathrm{EGTA}, 10 \%$ glycerol, $1 \%$ digitonin for experiments with human leukemia- or lymphoma-derived cell lines). Lysates were run on SDS-PAGE gels, proteins transferred to polyvinylidenedifluoride membranes, which were probed with antibodies against caspase-2 (clones $10 \mathrm{C} 6$ and $11 \mathrm{~B} 4{ }^{6}{ }^{6}$ Enzo Life Sciences, Farmingdale, NY, USA; Novus, Littleton, CO, USA; Y61 \#NB110-55655; Abcam, Cambridge, MA, USA; \#ab18737), total caspase-3 (clone 8G10), cleaved (i.e. activated) caspase-3 (Cell Signalling, Danvers, MA, USA) and $\beta$-actin (AC15, Sigma; used as a loading control).

\section{Conflict of Interest}

The authors declare no conflict of interest.

Acknowledgements. We are grateful to Drs D Vaux, J Adams, J Silke, $\mathrm{G}$ Dewson and $\mathrm{F} \mathrm{Ke}$ for helpful comments, cells and reagents. This work was supported by NHMRC Senior Principal Research Fellowships to AS (1020363), and SK (1002863), a South Australian Cancer Research Collaborative Fellowship (LD), and by program grant (1016701) and project grants (1022916, 1021456, 1043057 and 1009145) from the NHMRC (Australia), a SCOR grant (7417-07) from the Leukemia and Lymphoma Society, Victorian State Government Operational Infrastructure Support and the Australian Government NHMRC Independent Research Institute Infrastructure Support Scheme.
1. Smith $\mathrm{MH}$, Ploegh $\mathrm{HL}$, Weissman JS. Road to ruin: targeting proteins for degradation in the endoplasmic reticulum. Science 2011; 334: 1086-1090.

2. Puthalakath $H$, O'Reilly LA, Gunn $P$, Lee L, Kelly PN, Huntington ND et al. ER stress triggers apoptosis by activating BH3-only protein Bim. Cell 2007; 129: 1337-1349.

3. Ghosh AP, Klocke BJ, Ballestas ME, Roth KA. CHOP potentially co-operates with FOXO3a in neuronal cells to regulate PUMA and BIM expression in response to ER stress. PloS One 2012; 7: e39586.

4. Kieran D, Woods I, Villunger A, Strasser A, Prehn JH. Deletion of the BH3-only protein puma protects motoneurons from ER stress-induced apoptosis and delays motoneuron loss in ALS mice. Proc Natl Acad Sci USA 2007; 104: 20606-20611.

5. Upton JP, Wang L, Han D, Wang ES, Huskey NE, Lim L et al. IRE1alpha cleaves select microRNAs during ER stress to derepress translation of proapoptotic Caspase-2. Science 2012; 338: 818-822.

6. O'Reilly L, Ekert P, Harvey N, Marsden V, Cullen L, Vaux D et al. Caspase-2 is not required for thymocyte or neuronal apoptosis even though cleavage of caspase-2 is dependent on both Apaf-1 and caspase-9. Cell Death Differ 2002; 9: 832-841.

7. Manzl C, Peintner L, Krumschnabel G, Bock F, Labi V, Drach M et al. PIDDosome-independent tumor suppression by Caspase-2. Cell Death Differ 2012; 19: 1722-1732.

8. Parsons MJ, McCormick L, Janke L, Howard A, Bouchier-Hayes L, Green DR. Genetic deletion of caspase-2 accelerates MMTV/c-neu-driven mammary carcinogenesis in mice. Cell Death Differ 2013; 20: 1174-1182.

9. Puccini J, Dorstyn L, Kumar S. Caspase-2 as a tumour suppressor. Cell Death Differ 2013; 20: $1133-1139$

10. Shalini S, Dorstyn L, Wilson C, Puccini J, Ho L, Kumar S. Impaired antioxidant defence and accumulation of oxidative stress in caspase-2-deficient mice. Cell Death Differ 2012; 19: $1370-1380$.

11. Lindsten T, Ross AJ, King A, Zong WX, Rathmell JC, Shiels HA et al. The combined functions of proapoptotic Bcl-2 family members bak and bax are essential for normal development of multiple tissues. Mol Cell 2000; 6: 1389-1399.

12. Rathmell JC, Lindsten T, Zong WX, Cinalli RM, Thompson CB. Deficiency in Bak and Bax perturbs thymic selection and lymphoid homeostasis. Nat Immunol 2002; 3: 932-939.

13. Youle RJ, Strasser A. The BCL-2 protein family: opposing activities that mediate cell death. Nat Rev Mol Cell Biol 2008; 9: 47-59.

14. Baliga BC, Read SH, Kumar S. The biochemical mechanism of caspase-2 activation. Cell Death Differ 2004; 11: 1234-1241.

15. Upton JP, Austgen K, Nishino M, Coakley KM, Hagen A, Han D et al. Caspase-2 cleavage of BID is a critical apoptotic signal downstream of endoplasmic reticulum stress. Mol Cell Biol 2008; 28: 3943-3951.

16. Dorstyn L, Puccini J, Wilson CH, Shalini S, Nicola M, Moore S et al. Caspase-2 deficiency promotes aberrant DNA-damage response and genetic instability. Cell Death Differ 2012; 19: $1288-1298$

17. Ho LH, Taylor R, Dorstyn L, Cakouros D, Bouillet $P$, Kumar $S$. A tumor suppressor function for caspase-2. Proc Natl Acad Sci USA 2009; 106: 5336-5341.

18. Bergeron L, Perez Gl, Macdonald G, Shi LF, Sun Y, Jurisicova A et al. Defects in regulation of apoptosis in caspase-2-deficient mice. Genes Dev 1998; 12: 1304-1314.

19. Marsden VS, Ekert PG, Van Delft M, Vaux DL, Adams JM, Strasser A. Bcl-2-regulated apoptosis and cytochrome $c$ release can occur independently of both caspase-2 and caspase-9. JCell Biol 2004; 165: 775-780.

20. Manzl C, Krumschnabel G, Bock F, Sohm B, Labi V, Baumgartner $F$ et al. Caspase-2 activation in the absence of PIDDosome formation. J Cell Biol 2009; 185 : 291-303.

21. Mason KD, Lin A, Robb L, Josefsson EC, Henley KJ, Gray DH et al. Proapoptotic Bak and Bax guard against fatal systemic and organ-specific autoimmune disease. Proc Natl Acad Sci USA 2013; 110: 2599-2604.

22. Ho LH, Read SH, Dorstyn L, Lambrusco L, Kumar S. Caspase-2 is required for cell death induced by cytoskeletal disruption. Oncogene 2008; 27: 3393-3404.

23. Ekert PG, Jabbour AM, Manoharan A, Heraud JE, Yu J, Pakusch $M$ et al. Cell death provoked by loss of interleukin-3 signaling is independent of Bad, Bim, and PI3 kinase, but depends in part on Puma. Blood 2006; 108: 1461-1468.

24. O'Reilly LA, Kruse EA, Puthalakath H, Kelly PN, Kaufmann T, Huang DC et al. MEK/ERK-mediated phosphorylation of Bim is required to ensure survival of $T$ and $B$ lymphocytes during mitogenic stimulation. J Immunol 2009; 183: 261-269. 